УДК 629.487

DOI 10.47049/2226-1893-2020-1-97-105

\title{
ОБЕСПЕЧЕНИЕ ЭКСПЛУАТАЦИОННЫХ ХАРАКТЕРИСТИК ВЫСОКОПЛОТНЫХ ТЕХНИЧЕСКИХ ЖИДКОСТЕЙ ПРИ ИХ ТРАНСПОРТИРОВКЕ МОРСКИМИ СУДАМИ
}

\author{
С.А. Карьянский \\ к.т.н., доцент \\ Д.Н. Марьянов \\ аспирант \\ Национальный университет «Одесская морская академия», \\ Одесса, Украина
}

Аннотация. Рассмотрен способ поддержания реологических характеристик высокоплотных технических жидкостей, при их длительном транспортировании специализированными морскими судами. Установлено, что стратификация плотности по глубине грузового танка в диапазоне времени транспортирования 6-24 часов находится в пределах 9,2-48\%. Предложен способ обеспечения дополнительной цุиркуляичи технических жидкостей в грузовых танках. Экспериментально подтверждено, что при этом стратификации плотности уменьшается до 0,4-1,5\%.

Ключевые слова: технические жидкости, спечиилизированное судно, реологические характеристики, седиментация, стратификация плотности.

УДК 629.487

DOI 10.47049/2226-1893-2020-1-97-105

\section{ЗАБЕЗПЕЧЕННЯ ЕКСПЛУАТАЦЙНИХ ХАРАКТЕРИСТИК ТЕХНІЧНИХ РІДИН З ВИСОКОЮ ГУСТИНОЮ ПРИ ЇХ ТРАНСПОРТУВАННІ МОРСЬКИМИ СУДНАМИ}

\author{
С.А. Кар'янський \\ к.т.н., доцент \\ Д.М. Мар'янов \\ аспірант
}

Національний університет «Одеська морська академія», Одеса, Украӥна

Анотація. Розглянуто спосіб підтримки реологічних характеристик технічних рідин з високою густиною, при їх тривалому транспортуванні спеціалізованими морськими судами.

() Карьянский С.А., Марьянов Д.М., 2020 
Встановлено, що стратифікаиія густини за глибиною вантажного танка в діапазоні часу транспортування 6-24 годин знаходиться в межах 9,2-48\%. Запропоновано спосіб забезпечення додаткової ииркуляиіі технічних рідин у вантажних танках. Експериментально підтверджено, що при иььому стратифікаиії густини зменшується до 0,4-1,5\%.

Ключові слова: технічні рідини, спеціалізоване судно, реологічні характеристики, седиментація, стратифікаиія густини.

УДК 629.487

DOI 10.47049/2226-1893-2020-1-97-105

\title{
ENSURING THE OPERATIONAL CHARACTERISTICS OF HIGH-DENSITY TECHNICAL FLUIDS DURING THEIR TRANSPORTATION BY SEA VESSELS
}

\author{
S. Karianskyi \\ Candidate of Technical Sciences, Associate Professor \\ D. Maryanov \\ Postgraduate
}

National University «Odessa Maritime Academy», Odessa, Ukraine

\begin{abstract}
It is shown that the annual increase in the consumption of hydrocarbons, the prevalence of the use of liquid and gaseous fuels over solid fuels, and the absence of real alternatives to oil and gas as the main source of thermal energy leads to the gradual depletion of their continental deposits. A further increase in energy consumption in industry, transport and in everyday life increases the shortage of fuel of petroleum origin, which can be provided only by continental reserves. Therefore, in recent years, a large number of countries have been developing and expanding the development of resources on the continental shelf and the World Ocean.

It is proved that drilling operations on offshore and offshore oil production platforms are associated with the use of special technical fluids (in particular, drilling slurries), which ensure the functioning, lubrication and cooling of underwater equipment.

It is indicated that the delivery of such liquids to drilling platforms is carried out by marine specialized vessels that transport them in cargo tanks. Taking into account practical experience, it was shown that the time of their transportation can reach 7-10 days, which contributes to the deterioration of their functional characteristics due to stratification, but also contributes to the formation of dense silicon organic and graphite compounds at the bottom of the cargo tank. It was found that density stratification along the depth of a cargo tank depending on the transportation time can be: 9,2\% (for 6 hours), $19,5 \%$ (for 12 hours), 32,9\% (for 18 hours), 48,0\% (for 24 hours).
\end{abstract}


A method for maintaining the rheological characteristics of highdensity liquids is proposed. It has been experimentally confirmed that maintaining the density of technical fluids and ensuring a minimum level of density stratification (in the range of 0,4-1,5\% with a transport time of 6-24 hours) can be ensured by their additional circulation in the volume of the cargo tank.

A system has been developed that provides additional circulation of technical fluids, and can be installed on a specialized vessel in accordance with the technological scheme directly by the ship's crew. It was established that the power required for the functioning of this system does not significantly affect the energy performance of a ship power electrostation.

Keywords: technical fluids, specialized vessel, rheological characteristics, sedimentation, density stratification.

Постановка проблемы в общем виде. Ежегодное увеличение потребления углеводородного сырья, превалирование использования жидкого и газообразного топлива над твердым, отсутствие реальных альтернатив нефти и газу как основному источнику тепловой энергии приводит к постепенному истощению их континентальных месторождений. Дальнейший рост потребления энергии в промышленности, на транспорте и в повседневной жизни повышает дефицит топлива нефтяного происхождения, который может быть обеспечен только континентальными запасами. Поэтому в последнее время большое количество стран развивают и расширяют освоение ресурсов континентального шельфа и Мирового океана. При этом до́быча углеводородного сырья осуществляется на автономных буровых платформах, расположенных вне материковых территорий, а поэтому требующих доставки на них специального оборудования, техники и материалов.

Проведение буровых работ на морских и океанских нефтедобывающих платформах связано с использованием специальных технических жидкостей (в частности бурильных суспензий), которые обеспечивают функционирование, смазывание и охлаждение подводного оборудования. Как правило, эти жидкости состоят из высоковязких масел, в которые дополнительно добавляются металлы (как в чистом виде, так и в виде солей или оксидов), соединения кремния и графита. Это увеличивает их плотность, вязкость, а также существенно изменяет реологические характеристики [1]. Как и любой технический объект, эти жидкости характеризуются определенным эксплуатационным периодом, по истечении которого происходит их полная или частичная замена. Доставка таких жидкостей на буровые платформы выполняется морскими специализированными судами, которые осуществляют их транспортировку в грузовых танках. Время транспортирования зависит от удаленности буровой платформы от базового порта, скоростных характеристик судна, а также от внешних условий (погоды, ветра, волнения моря) и может 
достигать 7-10 дней. При этом, в связи с действием гравитационных сил, более тяжелые компоненты технических жидкостей постепенно осаждаются в грузовых танках. Это приводит не только к ухудшению их функциональных характеристик за счет расслоения, но и способствует образованию плотных кремний органических и графитовых соединений на дне грузового танка. Результатом этого может стать полное отсутствие текучести жидкости и не возможность ее транспортировки из грузового танка специализированного судна на буровую платформу [2].

Для ликвидации подобных последствий требуется значительное время (от нескольких часов до нескольких дней) на демонтаж системы перекачивания груза, очистку грузовых танков и восстановление реологических характеристик перевозимых технических жидкостей.

Анализ последних исследований и публикаций. Поддержание реологических характеристик бурильных суспензий, является актуальной прикладной задачей (поскольку обеспечивает надежное функционирование оборудования и беспрерывность процесса до́бычи и транспортировки углеводородного сырья), при этом ее решение, как правило, рассматривается и обеспечивается для континентальных месторождений, для условий, не учитывающих специфику транспортировки и передачи бурильных суспензий на морские или океанские буровые платформы [3; 4]. Вопросы обеспечения функциональных свойств и эксплуатационных характеристик подобных технических жидкостей применительно к морской отрасли практически не изучены; правила их транспортировки не имеют подтвержденных практических рекомендаций; латентное ухудшение их реологических показателей (вязкости, плотности, седиментационной стойкости) не всегда может быть определено, оценено и устранено судовым экипажем [5].

Постановка задачи. Задачей исследования являлось определение стратификации плотности технических жидкостей (бурильных суспензий) при их транспортировке в танках специализированного морского судна с последующей разработкой практических рекомендаций по обеспечению минимального уровня данной стратификации.

Изложение основного материала исследований. Экспериментальные исследования выполнялись на морском специализированном судне, обеспечивающем снабжение нефтедобывающих платформ.

В процессе транспортировки бурильных суспензий ввиду непрерывно происходящего процесса седиментации (из-за легирования суспензии частицами грубодисперсных систем) происходит их расслаивание [6]. Предотвращение подобных явлений возможно за счет путем организации их дополнительной циркуляции в объеме грузового танка при непрерывном или периодическом контроле эксплуатационных и реологических характеристик (например, плотности). Технологическое обеспечение этой идеи продемонстрировано на рис. 1. 


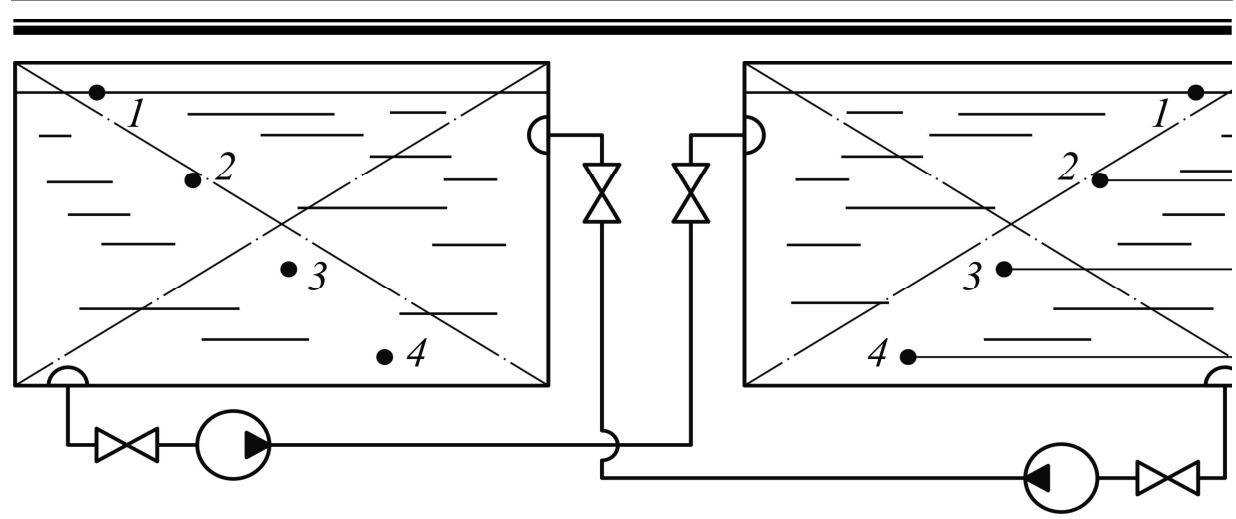

Рис. 1. Схема обеспечения дополнительной цииркуляции и контроля плотности технических жидкостей, перевозимых в грузовых танках специализированных судов

Дополнительная X-образная циркуляция технической жидкости в грузовых танках обеспечивается двумя насосами, с помощью которых происходит движение жидкости из нижней части одного танка в верхнюю часть другого. Это поддерживает однородное состояние технической жидкости как в танке, так и всего объема технической жидкости, передаваемой в последствии на буровую платформу. Контроль реологических характеристик технической жидкости осуществляется путем измерения плотности в различных точках грузового танка (точки $1,2,3,4$ на рис. 1). При этом, плотность жидкости в точке $l$ соответствует плотности на поверхности, в точке 2 - на уровне $30 \%$ от общей высоты столба жидкости $-0,3 h$, в точке 3 - на уровне $-0,6 h$, в точке 4 - на уровне $-0,9 h$.

Конструкция специализированного судна и технология транспортирования технической жидкости предусматривала ее перевозку в четырех равноразмерных грузовых танках. В двух из них выполнялась модернизация (устанавливалась система дополнительной циркуляции в соответствии с рис. 1). Перевозка технической жидкости в двух других танках производилась в обычных условиях, без их модернизации. В обеих парах грузовых танков выполнялся контроль плотности технической жидкости на разной высоте (в точках $1,2,3,4$ - рис. 1) в следующем интервале времени: $6,12,18,24$ часа. Усредненные результаты измерения в одинаковых точках двух однотипных танков приведены в таблице 1.

По результатам, приведенным в таблице 1, построены номограммы, отражающие изменение плотности бурильной суспензии во времени в разных по высоте танках точках измерения (рис. 2).

Выводы и перспективы дальнейших исследований. Анализ приведенных результатов позволяет сделать следующие выводы. 
Изменение плотности технической жидкости ( $\left.\rho, \kappa^{2} / \mathrm{m}^{3}\right)$ в зависимости от времени ее транспортировки

\begin{tabular}{|c|c|c|c|c|c|c|c|c|c|c|}
\hline \multirow{2}{*}{$\begin{array}{c}\text { Уровень, } \\
\text { на котором } \\
\text { выполняется } \\
\text { измерение }\end{array}$} & \multicolumn{4}{|c|}{$\begin{array}{c}\text { Транспортировка } \\
\text { без циркуляции }\end{array}$} & \multicolumn{5}{c|}{$\begin{array}{c}\text { Транспортировка } \\
\text { дополнительной } \\
\text { циркуляцией }\end{array}$} \\
\cline { 2 - 11 } & \multicolumn{3}{|c|}{ время транспортировки, часы } & \multicolumn{3}{c|}{ время транспортировки, часы } \\
\cline { 2 - 11 } & 0 & 6 & 12 & 18 & 24 & 0 & 6 & 12 & 18 & 24 \\
\hline $\begin{array}{c}\text { на } \\
\text { поверхности }\end{array}$ & 1240 & 1185 & 1108 & 1043 & 982 & 1240 & 1238 & 1232 & 1234 & 1235 \\
\hline $0,3 h$ & 1240 & 1252 & 1235 & 1173 & 1065 & 1248 & 1242 & 1245 & 1237 & 1243 \\
\hline $0,6 h$ & 1246 & 1265 & 1282 & 1312 & 1376 & 1242 & 1240 & 1244 & 1243 & 1247 \\
\hline $0,9 h$ & 1250 & 1294 & 1324 & 1386 & 1453 & 1238 & 1243 & 1246 & 128 & 1253 \\
\hline
\end{tabular}

1. В процесс транспортирования специализированными судами к буровым платформам высокоплотных жидкостей, легированных тяжелыми металлами, в результате процесса седиментации происходит латентное изменение их плотности по высоте слоя. Это вызвано неоднородностью данных жидкостей и воздействием гравитационных сил на компоненты, имеющие больший удельный вес (металлы, их соли и оксиды, а также другие грубодисперсные составляющие).

2. Седиментация высокоплотных жидкостей (бурильных суспензий) в грузовых танках приводит к возникновению стратификации плотности жидкости, находящейся в грузовом танке, и выпадению более тяжелых компонентов в осадок, который накапливается на дне танка. При этом стратификация вязкости по глубине грузового танка в зависимости от времени транспортировки может составлять: 9,2\% (для 6 часов), $19,5 \%$ (для 12 часов), 32,9 \% (для 18 часов), 48,0 \% (для 24 часов). Это вызывает изменение реологических характеристик технических жидкостей - расслоение и уменьшение текучести, что затрудняет и даже может сделать невозможным процесс их перекачивания на буровые платформы.

3. Поддержание реологических характеристик (плотности) технических жидкостей и обеспечение минимального уровня стратификации плотности (в диапазоне 0,4-1,5 \% при времени транспортирования 6-24 часов) может быть обеспечено путем их дополнительной циркуляции в объеме грузового танка. При этом необходимо постоянно или периодически осуществлять контроль их плотности по глубине общего объема.

4. Система, обеспечивающая дополнительную циркуляцию технических жидкостей, включает циркуляционный насос, трубопроводы и арматуру и может быть установлена на специализированном судне в соответствии с технологической схемой непосредственно судовым экипажем. 


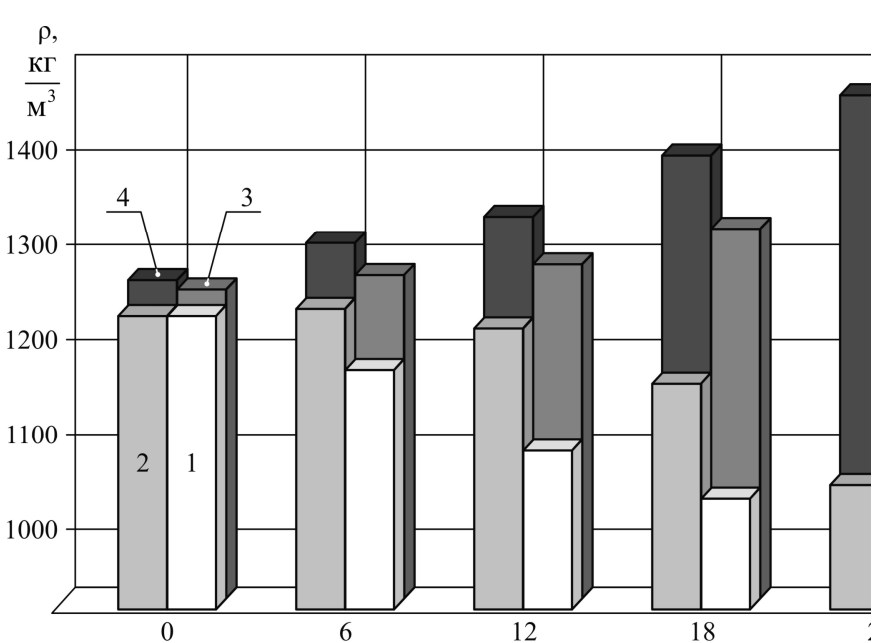

a)

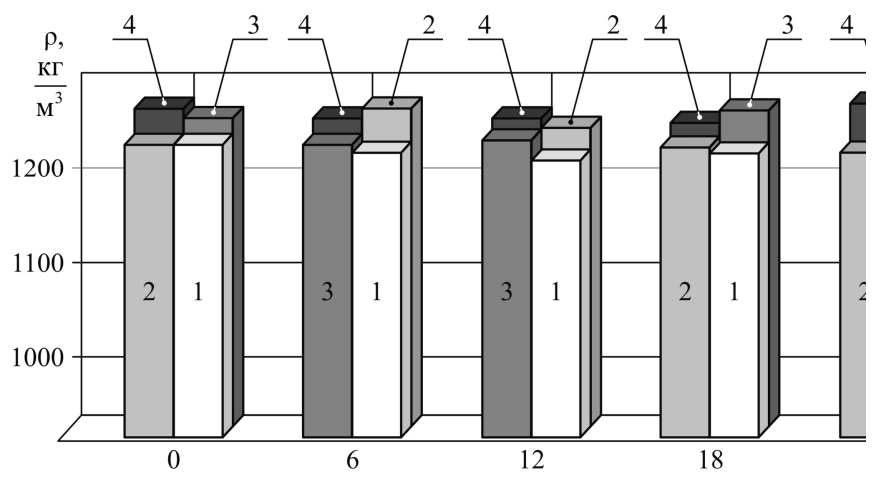

б)

Рис. 2. Стратификация плотности бурильной суспензии при различных условиях ее транспортировки:

а) без циркуляции; б) с дополнительной цииркуляциией;

1 - плотность жидкости на поверхности танка;

2 - на глубине $30 \%$ общего объема;

3 - на глубине $60 \%$; 4-на глубине $90 \%$

Мощность, необходимая для работы циркуляционных насосов, не оказывает существенного влияния на энергетические показатели судовой электростанции, которая для специализированных судов, обеспечивающих работу буровых платформ, характеризуется повышенными значениями и большим коэффициентом запаса.

Предложенная технология может быть использована на специализированных морских судах, обеспечивающих функционирование морских буровых платформ континентального шельфа и морского дна. 


\section{СПИСОК ЛІТЕРАТУРИ}

1. Поповский А.Ю. Оченка эксплуатаџионных свойств смазочно-охлаждающих жидкостей судовых технических средств / А.Ю. Поповский, С. В. Сагин // Автоматизация судовых технических средств: научн.-техн. сборник. 2016. Bbin. 22. C. 66-74.

2. Karianskyi S.A. Features of transportation of high-density technical liquids by marine specialized vessels / S.A. Karianskyi, D. M. Maryanov // Materials of the International Conference "Scientific research of the SCO countries: synergy and integration» January 25, 2020. Part 2. Beijing, PRC. P. 150-153. DOI. 10.34660/INF. 2020.24.53688.

3. Искендерадзе А.Э. К.О некоторых факторах, влияющих на стабильность буровых растворов / А.Э.К. Искендерадзе // Строительство нефтяных и газовых скважин на суше и на море, 2014. № 8. C. 40-42.

4. Сагин С.В. Оптические характеристики граничных смазочных слоев масел, применяемых в ииркуляционных системах судовых дизелей / С.В. Сагин, Д.В. Маикевич // Судовые энергетические установки: научн.-техн.сб. 2011. № 26. Одесса: OHMA. C.116-125.

5. Sagin S.V. Estimation of Operational Properties of Lubricant Coolant Liquids by Optical Methods / S.V. Sagin, V.G. Solodovnikov // International Journal of Applied Engineering Research. 2017. Vol. 12. Num. 19. P. 8380-8391.

6. Сагин С.В. Определение диапазона стратификаџии вязкости смазочного материала в трибологических системах судовых дизелей / С.В. Сагин // Вісник Одеськ. наи. мор. ун-ту, 2019. Bun. 1(58). C. 88-98.

7. Budashko V.V. Physical model of degradation effect by interaction azimuthal flow with hull of ship / V.V. Budashko, V.V. Nikolskyi, O.A. Onishchenko, S.N. Khniunin // Proceeding Book of International conference on engine room simulators (ICERS12), 2015. № 3 (8). P. 49-53.

\section{REFERENCES}

1. Popovskii A.Yu., Sagin S.V. (2016) Ocenka ekspluatacionnyh svojstv smazochno-ohlazhdayushih zhidkostej sudovyh tehnicheskih sredstv [Evaluation of the operational properties of cutting fluids of marine technical equipment]. Avtomatizaciya sudovyh tehnicheskih sredstv: nauchno-tehnicheskij sbornik, no. 22, pp. 66-74. 
2. Karianskyi S.A., Maryanov D.M. (2020) Features of transportation of high-density technical liquids by marine specialized vessels. Materials of the International Conference "Scientific research of the SCO countries: synergy and integration, Beijing, PRC, part 2, pp. 150-153. DOI. 10.34660/INF. 2020.24.53688.

3. Iskenderadze A. E. K. (2014) O nekotoryh faktorah, vliyayushih na stabilnost burovyh rastvorov [On some factors affecting the stability of drilling fluids] / A. Э. К. Искендерадзе // Stroitelstvo neftyanyh i gazovyh skvazhin na sushe i na more, no. 8, pp. 40-42 (in Russion)

4. Sagin S.V., Matskevich D.V. (2011). Opticheskie harakteristiki granichnyh smazochnyh sloev masel, primenyaemyh $v$ cirkulyacionnyh sistemah sudovyh dizelej [Optical characteristics of boundary lubricating layers of oils used in marine diesel circulating systems]. Sudovye energeticheskie ustanovki: nauchno-tehnicheskij sbornik, no. 26, pp. 116-125.

5. Sagin S.V., Solodovnikov V.G. (2017) Estimation of Operational Properties of Lubricant Coolant Liquids by Optical Methods. International Journal of Applied Engineering Research, vol. 12, no. 19, pp. 8380-8391.

6. Sagin S. V. (2019) Opredelenie diapazona stratifikacii vyazkosti smazochnogo materiala $v$ tribologicheskih sistemah sudovyh dizelej [Determination of the viscosity stratification range of the lubricant in tribological systems of ship diesel engines]. Visnyk Odeskogo nacionalnogo morskogo unyversytetu, no. 1(58), pp. 88-98.

7. Budashko V.V., Nikolskyi V.V., Onishchenko O.A., Khniunin S.N. (2015) Physical model of degradation effect by interaction azimuthal flow with hull of ship. Proceeding Book of International conference on engine room simulators (ICERS12), no. 3(8), pp. 49-53.

Стаття надійшла до редакиії 12.02.20

Посилання на статтю: Карьянский С.А., Марьянов Д.Н. Обеспечение эксплуатационных характеристик высокоплотных технических жидкостей при их транспортировке морскими судами // Вісник Одеського національного морського університету: Зб. наук. праць, 2020. № 1(61). С. 97-105. DOI 10.47049/2226-1893-2020-1-97-105.

Article received 12.02.20

Reference a JournalArtic: Karianskyi, S., Maryanov, D. Ensuring the operational characteristics of high-density technical fluids during their transportation by sea vessels. 1(61), 97-105. Herald of the Odessa national maritime university. DOI 10.47049/2226-1893-2020-1-97-105. 